\title{
SIMULATION OF NANOFLUIDS LAMINAR FLOW IN A VERTICAL CHANNEL
}

\author{
${ }^{1}$ Mohammed Saad KAMEL, ${ }^{2}$ Ferenc LEZSOVITS \\ ${ }^{1,2}$ Department of Energy Engineering, Faculty of Mechanical Engineering, Budapest \\ University of Technology and Economics, 1111 Budapest, Müegyetem rkp.3, Hungary \\ e-mail: ${ }^{1}$ kamel@energia.bme.hu, ${ }^{2}$ lezsovits@energia.bme.hu \\ ${ }^{1}$ Department of Mechanical Techniques, Al-Nasiriya Technical Institute, Southern Technical \\ University, 64001 Thi-Qar, Baghdad Street, Iraq, e-mail: kamel86@stu.edu.iq
}

Received 5 December 2017; accepted 12 March 2018

\begin{abstract}
In the present study, fully developed laminar flow with forced convection heat transfer of $\mathrm{Al}_{2} \mathrm{O}_{3}$ /water and $\mathrm{TiO}_{2}$ /water nanofluids inside a vertical tube subjected by constant heat flux from the wall was numerically analyzed using Ansys Fluent release 17.2. In this work, the single-phase model was proposed to simulate the water and nanofluids heat transfer characteristics; spherical nanoparticles with a constant diameter equal to $30 \mathrm{~nm}$ are used. The study has been carried out on a Reynolds number with ranges (400-2000) and nanoparticles volume concentration up to $1.5 \%$. the results show that the average Nusselt number for nanofluid is higher than that the base fluid (water) especially for $\mathrm{TiO}_{2} /$ water nanofluid, the Nusselt number increased with increasing Reynolds number and volume concentration in all cases. The enhancement ratio for nanofluids compared to water at different volume friction was studied; the higher improvement is about $3.51 \%$ for $\mathrm{TiO}_{2}$ /water nanofluid with $1.5 \%$ volume fraction. Moreover, a study for pressure drop along vertical tube was discussed.
\end{abstract}

Keywords: Laminar flow, Single-phase model, $\mathrm{Al}_{2} \mathrm{O}_{3} /$ water nanofluid, $\mathrm{TiO}_{2} /$ water nanofluid and Nusselt number

\section{Introduction}

Improved performance of heat exchange systems has been a topic of many investigations in past decades by means both experimentally and theoretically for single and two-phase flow applications [1], [2]. Passive methods for intensifying heat transfer play a significant role to improve heat transfer performance among others. However, traditional ways to increase heat transfer with expanding surface area have a limited impact, mainly when looking for devices miniaturization and compactness. On the other 
hand, conventional heat transfer fluids like water, ethylene glycol, and mineral oils have inherently poor thermal transport properties especially the thermal conductivity compared with solid materials. With recent progress in nanotechnology, the possibility for producing materials in nanometer-scale became secure and new heat transfer fluids are prepared termed as nanofluids. Nanofluids are suspension liquids that including dispersing nanoparticles with a range (1-100 nm) and have thermal conductivity better than conventional fluids [3]-[6]. Choi and Eastman. [7], they were the first group used nanofluid at Argonne National Laboratory, USA, about two decades ago.

Heris et al. [8], [9] studied experimentally the heat transfer of an equilateral triangular duct and circular tube by employing an $\mathrm{Al}_{2} \mathrm{O}_{3}$ /water nanofluid in laminar flow and under constant heat flux conditions. They found that the experimental heat transfer coefficient of $\mathrm{Al}_{2} \mathrm{O}_{3}$ /water nanofluid is higher than that of distilled water. Their results also indicate that the heat transfer enhancement increases with increases in the nanofluid volume concentration and Peclet number as well. Yu et al. [10] investigated numerically the developing of laminar forced convection flows by using $\mathrm{Al}_{2} \mathrm{O}_{3}$ /water through a circular compact pipe with constant heat flux. Their results show that Nusselt number and heat transfer rate are improved as the $\mathrm{Al}_{2} \mathrm{O}_{3}$ volume fraction increased as well as Reynolds number. Hwang et al. [11] carried out an experimental study to measure the pressure drop and convective heat transfer coefficient of water-based $\mathrm{Al}_{2} \mathrm{O}_{3}$ nanofluid flowing through a uniformly heated circular tube in the fully developed laminar flow regime. They showed that the convective heat transfer coefficient of the nanofluids increases by up to $8 \%$ at a concentration of $0.3 \mathrm{vol} . \%$ compared with that of pure water. Wen and Ding [12] studied the convective heat transfer of nanofluids at the entrance region under laminar flow conditions. Their results showed considerable enhancement of convective heat transfer using the $\gamma-\mathrm{Al}_{2} \mathrm{O}_{3}$ nanoparticles and de-ionized water as nanofluid compared with basefluid. Pak and Cho [13] examined heat transfer performance of $\mathrm{Al}_{2} \mathrm{O}_{3}$ and $\mathrm{TiO}_{2}$ nanoparticles suspended in water and expressed that the convective heat transfer coefficient enhanced compared to water at $3 \%$ volume fraction.

In this study, the heat transfer performance of two types of nanofluids in a vertical pipe with different nanoparticles volume friction $(0.5,1.0$ and 1.5$)$ vol. $\%$ was studied. Laminar flow regime with a range of Reynolds number 400-2000 was selected to predict the behavior of water and nanofluids along the vertical tube.

\section{Governing equations and assumption}

It can be assumed that the flow is fully developed laminar forced convection and steady state flow of an incompressible and viscous (Newtonian) fluid, the governing equations for the single phase model can be written as follows [14]:

\section{Continuity equation}

$$
\frac{\partial u}{\partial x}+\frac{\partial v}{\partial y}=0
$$


Momentum equation

$$
\begin{aligned}
& u \frac{\partial u}{\partial x}+v \frac{\partial u}{\partial y}=-\frac{1}{\rho_{e f f}} \frac{\partial p}{\partial x}+v_{e f f}\left(\frac{\partial^{2} u}{\partial x^{2}}+\frac{\partial^{2} u}{\partial y^{2}}\right)-\rho g_{x} \\
& u \frac{\partial v}{\partial x}+v \frac{\partial v}{\partial y}=-\frac{1}{\rho_{e f f}} \frac{\partial p}{\partial x}+v_{e f f}\left(\frac{\partial^{2} v}{\partial x^{2}}+\frac{\partial^{2} v}{\partial y^{2}}\right)-\rho g_{y}
\end{aligned}
$$

where $p$ is the static pressure and $\rho \mathbf{g}$ is the gravitational body force term; $u, v$ are velocity components and $x, y$ are cartesian coordinates.

Energy equation

$$
u \frac{\partial T}{\partial x}+v \frac{\partial T}{\partial y}=\alpha_{e f f}\left(\frac{\partial^{2} T}{\partial x^{2}}+\frac{\partial^{2} T}{\partial y^{2}}\right)
$$

where $\rho_{\text {eff }}, v_{\text {eff }}, \alpha_{\text {eff }}=\frac{\lambda_{\text {eff }}}{\rho_{\text {eff }} \cdot C_{p, e f f}}$ are the density, kinematic viscosity and thermal diffusivity of the effective fluid (nanofluid), respectively.

\section{Thermo-physical properties of nanofluids}

The effective mass density of the nanofluid is $\rho_{\text {eff }}$ is calculated using:

$$
\rho_{e f f}=(1-\varphi) \rho_{f}+\varphi \rho_{p}
$$

where, $\varphi, \rho_{f}$ and $\rho_{p}$ are the volume friction of nanoparticles, mass densities of the base fluid and solid particles, respectively. The heat capacity at constant pressure per unit volume of the nanofluid $\left(\rho C_{p}\right)_{\text {eff }}$ is calculated as:

$$
\left(\rho C_{p}\right)_{e f f}=(1-\varphi)\left(\rho C_{p}\right)_{f}+\varphi\left(\rho C_{p}\right)_{p}
$$

where, $C_{p}$ is the specific heat at constant pressure, and $\left(\rho C_{p}\right)_{f},\left(\rho C_{p}\right)_{p}$ are the heat capacities at constant pressure per unit volume of the base fluid and solid particles, respectively. The effective specific heat at constant pressure of nanofluid $C_{p, e f f}$ is calculated as: 


$$
C_{p, e f f}=\frac{(1-\varphi)\left(\rho C_{p}\right)_{f}+\varphi\left(\rho C_{p}\right)_{p}}{(1-\varphi) \rho_{f}+\varphi \rho_{p}}
$$

The effective thermal conductivity of fluid has been determined by the temperature dependent model proposed by [15] and used by [16], [17] and [18]. For the twocomponent entity of spherical-particle suspension the model gives:

$$
\frac{k_{e f f}}{k_{f}}=1+\left(\frac{k_{s} A_{p}}{k_{f} A_{f}}\right)(1+c \cdot P e)
$$

where $\frac{A_{p}}{A_{f}}=\frac{d_{f}}{d_{p}} \frac{\varphi}{(1-\varphi)}, A_{p}, A_{f}$ represent the heat transfer area of particle and liquid medium respectively, $d_{p}, d_{f}$ are the molecular size of liquid and the particle diameter respectively; $c=25000$ is an experimental constant; $P e=\frac{u_{b} d_{p}}{a_{f}}$ and $\alpha_{f}$ is the thermal diffusivity of the base fluid; $u_{b}$ is the Brownian motion velocity of the nanoparticles, which is given by:

$$
u_{b}=\frac{2 k_{b} T}{\pi \mu_{f} d_{p}^{2}}
$$

where $k_{b}, \mu_{f}$ and $T$ are the Boltzmann constant, the dynamic viscosity of the liquid and the temperature of the particle, respectively.

The effective viscosity of nanofluid introduced by [13], [19] as follows:

$$
\frac{\mu_{e f f}}{\mu_{f}}=1+39.11 \varphi+533.9 \varphi^{2} .
$$

The percentage of heat transfer enhancement is calculated as:

$$
\text { Enhancemen t percentage }=\frac{N u_{n f}-N u_{f}}{N u_{n f}} \cdot 100,
$$

where $N u_{n f}, N u_{f}$ are the Nusselt number of nanofluid and basefluid respectively.

The thermo-physical properties of nanoparticles in this work are introduced by [19] as shown below in Table I. 
Table I

Thermophysical properties of water and nanoparticles at $300 \mathrm{~K}$

\begin{tabular}{|l|c|c|c|}
\hline \multicolumn{1}{|c|}{ Property } & Water & $\mathrm{Al}_{2} \mathrm{O}_{3}$ & $\mathrm{TiO}_{2}$ \\
\hline Density $\rho\left(\mathrm{kg} / \mathrm{m}^{3}\right)$ & 998.2 & 3970 & 4250 \\
\hline Specific heat $C_{p}(\mathrm{~J} / \mathrm{kg} . \mathrm{k})$ & 4182 & 765 & 686.2 \\
\hline Thermal conductivity $k(\mathrm{~W} / \mathrm{m} . \mathrm{k})$ & 0.6 & 40 & 8.9538 \\
\hline Viscosity $\mu\left(\mathrm{N} . \mathrm{s} / \mathrm{m}^{2}\right)$ & 0.001003 & - & - \\
\hline
\end{tabular}

\section{Physical geometry}

In the present study, a vertical heated tube with a length $(1.5 \mathrm{~m})$ and a circular cross section with the diameter $(0.01 \mathrm{~m})$ are reckoned as it is shown in Fig. 1. In order to get fully developed region the modeled tube was extended at the inlet region by $0.5 \mathrm{~m}$ unheated length. The working fluid is $\mathrm{Al}_{2} \mathrm{O}_{3} /$ water and $\mathrm{TiO}_{2} /$ water with $(30 \mathrm{~nm})$ nanoparticles diameter dispersed in water as a base fluid. In order to save computational time, the fluid flow and thermal field are assumed 2-Dimensional axisymmetric w.r.t the $x$-axis flow.

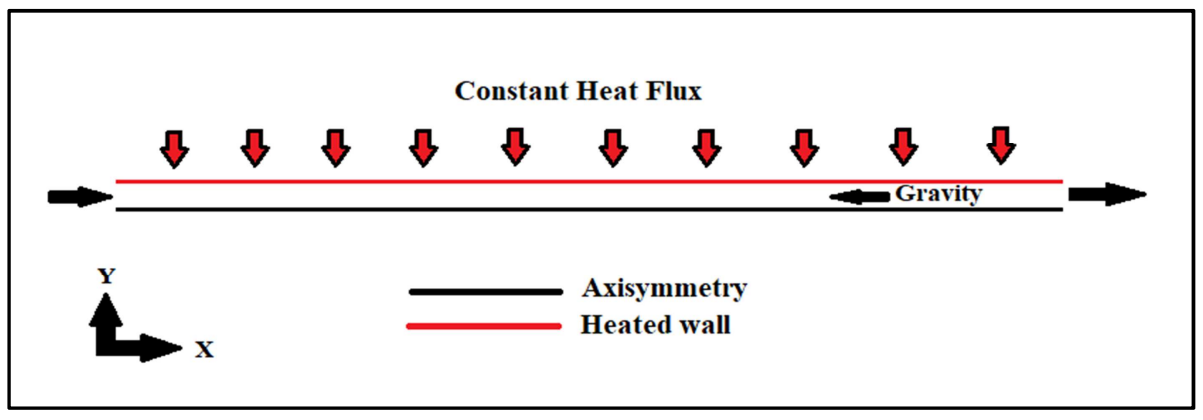

Fig. 1. The geometry of the physical domain

\section{Boundary condition}

The boundary conditions for this study are considered as follows:

1) At the inlet channel a uniform axial velocity $\left(v_{x}\right)$ based on Reynolds number and inlet temperature $(T)=300 \mathrm{~K}$, is assumed;

2) The velocity of solid particles is assumed same as that of water at the inlet channel (no slip velocity) for single-phase model simulation;

3) At the outlet channel pressure considered to be zero $P=0$;

4) On the top heated wall, non-slip conditions and uniform heat flux of $2000 \mathrm{~W} / \mathrm{m}^{2}$ are assumed. 


\section{Numerical method and grid test}

In the present study, the commercial Computational Fluid Dynamic (CFD) package of Ansys Fluent Release 17.2 has been used to solve equations for conservation of mass, momentum, and energy using a finite volume technique. The coupling between pressure and velocity is implemented by SIMPLEC algorithm. To reduce numerical errors, second-order upwind discretization schemes are used in the single-phase calculations. Grid sensitivity was tested in meshing tool available in Ansys 17.2 with structured mesh based on a quadrilaterals grid as it is shown in Fig. 2. Effect of grid size on the results was performed for water as working fluid; hence, three sets of the mesh are chosen which are 45000 cells, 90000 cells and 180000 cells with a Reynolds number 1600. As a result, the average Nusselt number comparing for all three-grid size and the percentage of relative error was less than $0.02 \%$ as shown in Fig. 3. Therefore, the second grid with 30000 cells was adopted to make a balance between the computational time and results accuracy of predicted data.

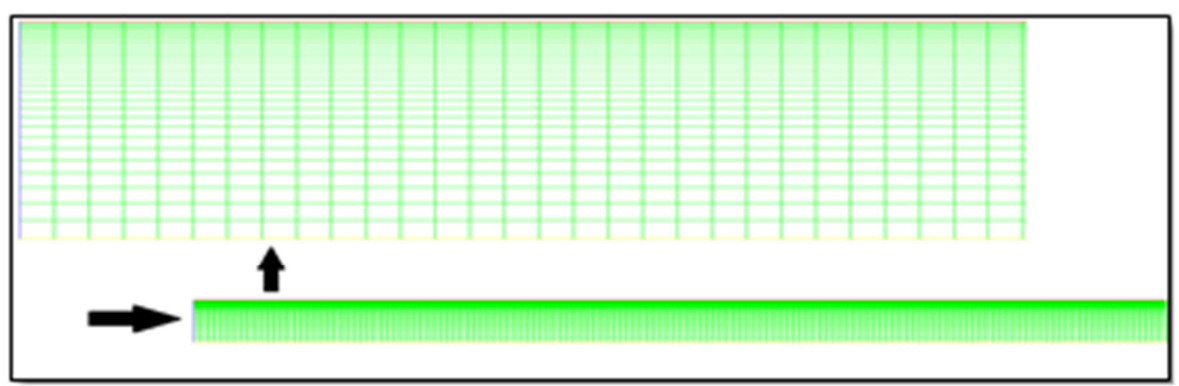

Fig. 2. Mesh structure in Ansys workbench 17.2

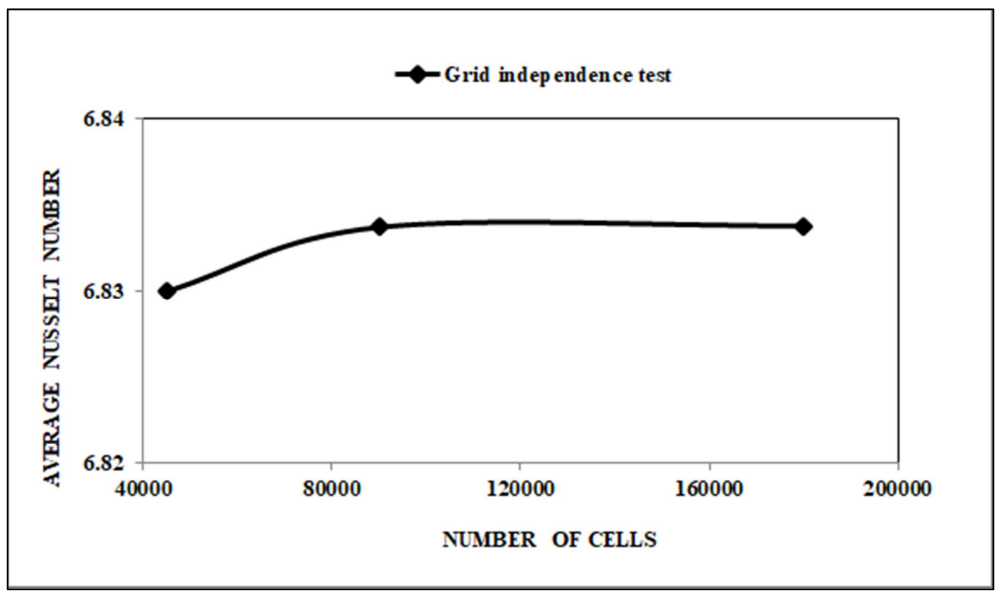

Fig. 3. Grid independence test for the model 


\section{Results and discussion}

In order to set up the accuracy of the numerical model, validation of average Nusselt number and friction factor for laminar forced convection of water flow inside the vertical tube with constant heat flux has been compared with the well-known correlation called Shah Correlation [20] that used by [11], [12],

$$
N u=\left\{\begin{array}{cc}
1.953 x_{*}^{-1 / 3}, & x_{*} \leq 0.03, \\
4.364+\frac{0.0722}{x_{*}}, & x_{*}>0.03,
\end{array}\right.
$$

where $x_{*}$ is the dimensionless longitudinal position as follows:

$$
x_{*}=\frac{L / D_{i n}}{\operatorname{Re}_{D} P r},
$$

where $L, D_{i n}, \operatorname{Re}_{D}$ and $P_{r}$ are the length of the tube, the inner diameter of the tube, Reynolds number and Prandtl number.

The average Nusselt number and Darcy friction factor along the heated wall are drawn as shown in Fig. 4 and Fig. 5 at different Reynolds number for laminar forced convection flow. Predicted results by numerical model show a good agreement with Shah Correlation [20] and acceptable agreement with Darcy friction factor for laminar flow.

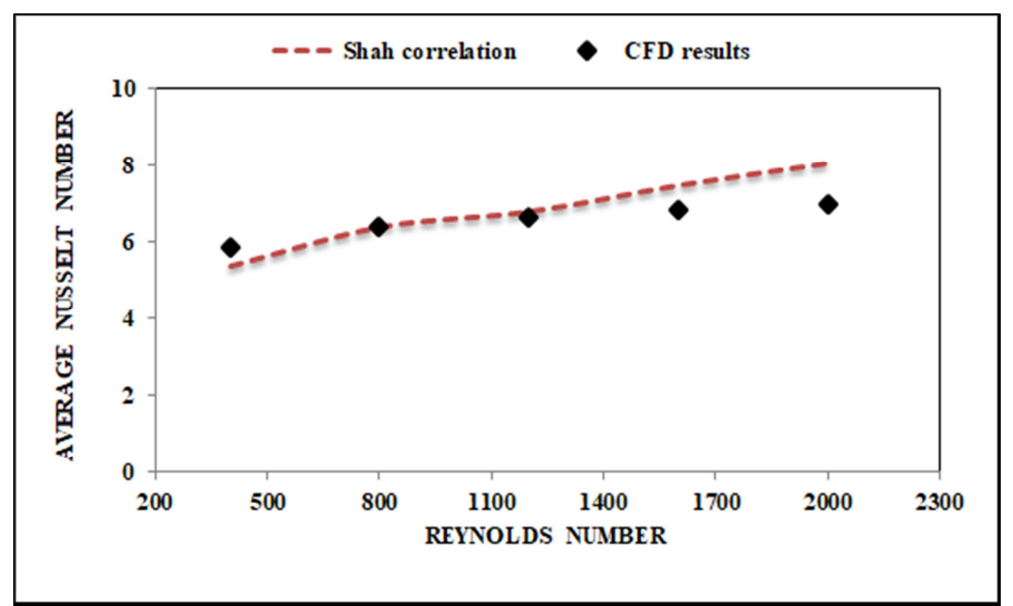

Fig. 4. Comparison of average Nusselt number for different Reynolds number for Shah equation and present model 


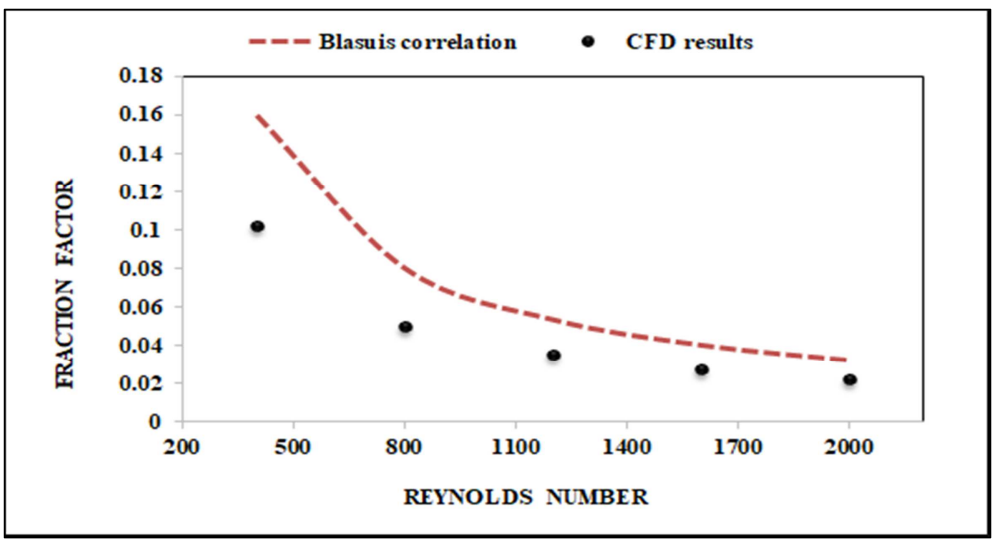

Fig. 5. Comparison of friction factor with Reynolds number for Blasius equation and present CFD model

After ensuring the validity and reliability of the numerical model, heat transfer measurements were performed for water and nanofluids at Reynolds numbers in the range of 400-2000 and concentration values of $0.1 \%$, and $0.3 \%$.

The relationships between Nusselt number and Reynolds number at different volume fraction are shown in Fig. 6 and Fig. 7. The results clearly show that the using $\mathrm{Al}_{2} \mathrm{O}_{3}$ /water and $\mathrm{TiO}_{2} /$ water nanofluids significantly enhance average Nusselt number, especially at entrance region and at high Reynolds number.

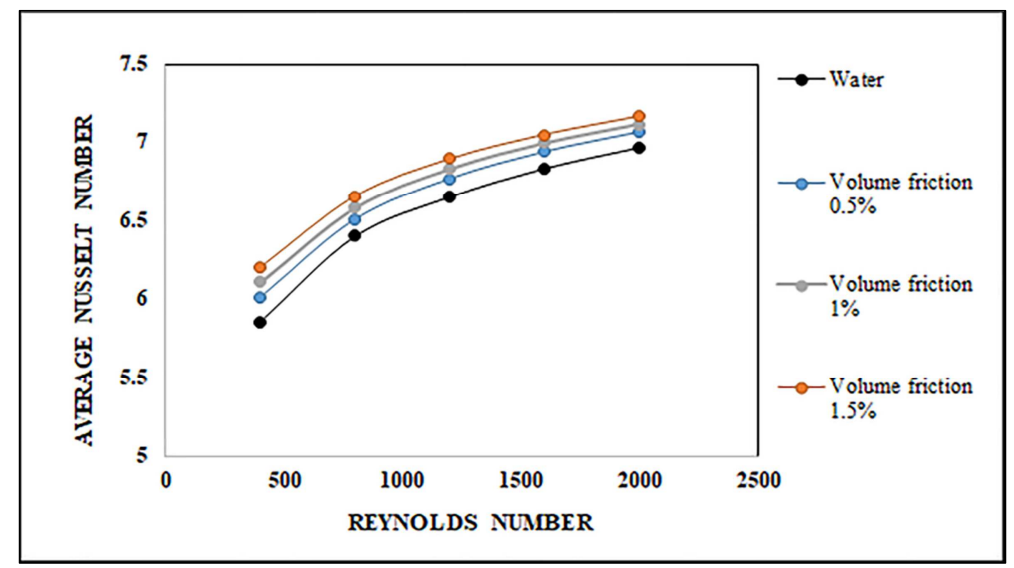

Fig. 6. Relationship between average Nusselt number and Reynolds number of water and $\mathrm{Al}_{2} \mathrm{O}_{3}$ /water nanofluid at different concentrations

It has been also shown that the increasing volume fraction of nanoparticles based water increased Nusselt number. A similar trend was also seen by researchers [12], [17] and [18] for heat transfer performance, because of the local Nusselt number depends on 
the local heat transfer coefficient and this, in turn, depend on thermal conductivities and the thickness of thermal boundary layer of nanofluids. These parameters play a significant role in the enhancement of heat transfer performance and because of improvement of thermal conductivities of nanofluids in this study Nusselt number increased noticeably.

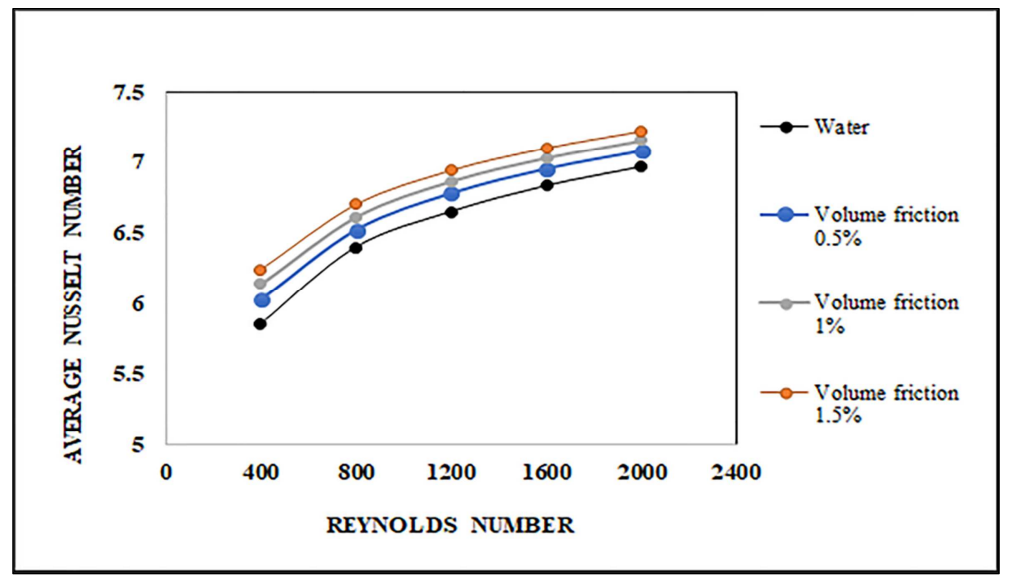

Fig. 7. Relationships between average Nusselt number with Reynolds number of water and $\mathrm{TiO}_{2}$ /water nanofluid at different concentrations

There are some reasons behind increasing thermal conductivity of nanofluid that introduced by many studies in the literature [7]-[12], [21] including the Brownian motion of particles, the interaction between particles and liquid layering, ballistic transport of energy carriers. One of the most important reasons to improve the heat transfer performance was the particles effect on developing the hydrodynamic and thermal layers along the channel length. Fig. 8 shows the relationship between the pressure drop and Reynolds number with the presence of different loading of two types of particles; it can be clearly seen that the pressure drop increased with a high volume concentration of particles at high Reynolds number.

The reason behind this increase in pressure drop because of friction factor increasing, friction factor depends primarily on the velocity, diameter of the pipe, density and viscosity as well. In nanofluids, the viscosity is higher than the basefluid due to adding solid particles, and this increasing depend on the volume concentration of those particles and size of particles as well. At high velocity (higher Reynolds number) the friction going to be increased because of high velocity of flow and then the pressure drop increases. Moreover, gravity effect and small temperature difference along the tube in this work also increase the pressure drop due to high friction and density for working fluids. Fig. 9 shows the enhancement ratio for both nanofluids compared with water and it can be clearly seen that the heat transfer enhancement is about $3.51 \%$ for $\mathrm{TiO}_{2} /$ water nanofluid with $1.5 \%$ volume fraction. 


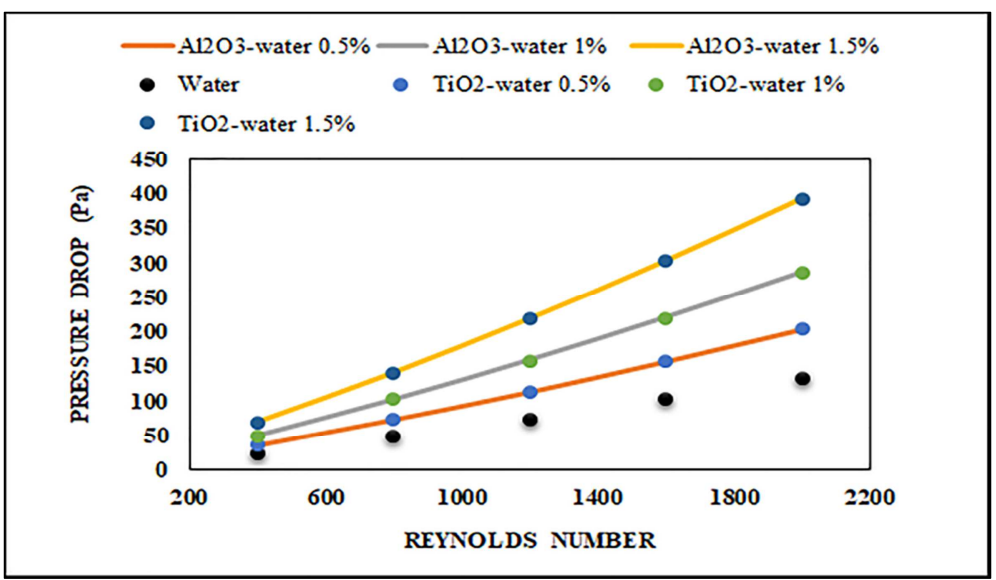

Fig. 8. Relationship of pressure drop with Reynolds number different working fluids

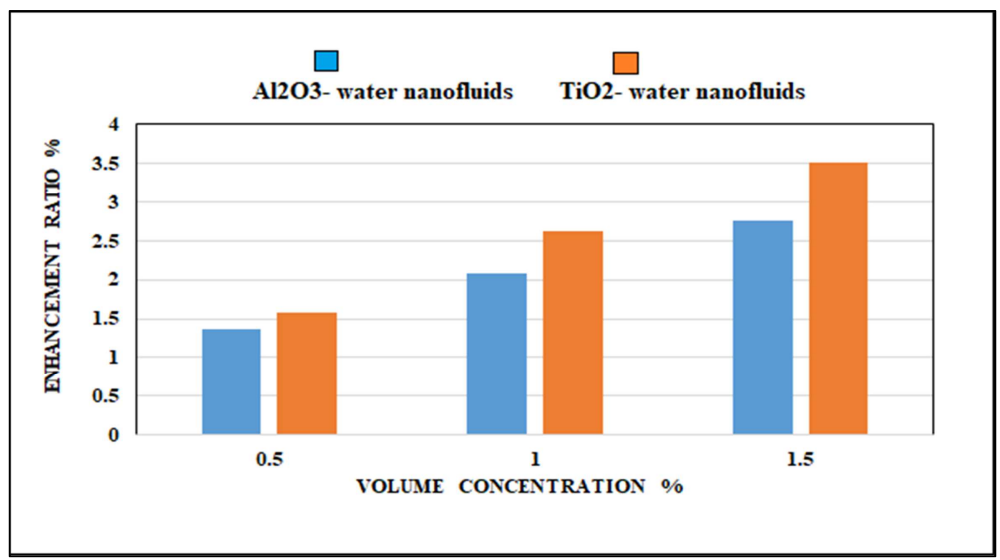

Fig. 9. Enhancement ratio with volume concentration for both nanofluids

\section{Conclusion}

In the present study, laminar forced convection heat transfer of $\mathrm{Al}_{2} \mathrm{O}_{3}$ and $\mathrm{TiO}_{2}$ nanoparticles based water nanofluids inside a vertical tube was numerically studied. The results of this work indicate that the use of $\mathrm{Al}_{2} \mathrm{O}_{3} /$ water and $\mathrm{TiO}_{2} /$ water nanofluids in a vertical pipe increases the heat transfer performance that represented by Nusselt number compared with water. It was also found that the nanofluids heat transfer improved with the higher Reynolds number and volume concentration as well. Furthermore, the enhancement ratio for both nanofluids compared to water at different volume friction was presented and the higher enhancement is about $3.51 \%$ for $\mathrm{TiO}_{2} /$ water nanofluid with $1.5 \%$ volume fraction. Finally, it was found that with increases of nanofluid 
concentration the pressure drop across the vertical pipe was also increased for both nanofluids compared with base fluid (water).

\section{Acknowledgements}

The authors are thankful to the Hungary Government for their financial support that is represented in the Stipendium Hungaricum Scholarship. In addition, the Authors would also like to thank the Tempus Public Foundation (TPF) in Hungary for their continued administrative support from application to graduation.

\section{References}

[1] Varga T., Szepesi G., Simenfalvi Z. Horizontal scraped surface heat exchanger Experimental measurements and numerical analysis, Pollack Periodica, Vol. 12, No. 1, 2017, pp. 107-122.

[2] Jancskar I., Ivanyi A. Phenomenological hysteresis model for vapor-liquid phase transitions, Pollack Periodica, Vol. 3, No. 1, 2008, pp. 5-28.

[3] Kamel M. S., Syeal R. A., Abdulhussein A. A. Heat transfer enhancement using nanofluids: A review of the recent literature, American J. of Nano Research and Applications, Vol. 4, No. 1, 2016, pp. 1-5.

[4] Mahian O., Kianifar A., Soteris A. K., Ioan P., Wongwises S. A review of the applications of nanofluids in solar energy, Int. J. of Heat and Mass Transf. Vol. 57, No. 2, 2013, pp. 582-94.

[5] Hussein A. M., Bakar R. A., Kadirgama K., Sharma K. V. Heat transfer enhancement using nanofluids in an automotive cooling system, Int. Commun in Heat and Mass Transf, Vol. 53, 2014, pp. 195-202.

[6] Kamel M. S., Lezsovits F. Boiling heat transfer of nanofluids: A review of recent studies, Thermal Science, 2017, DOI: https://doi.org/10.2298/TSCI170419216K.

[7] Choi S. U. S., Eastman J. A. Enhancing thermal conductivity of fluids with nanoparticles, International mechanical engineering congress and exhibition, San Francisco, CA (United States), 12-17 Nov 1995, FED-Vol. 231/MD-Vol. 66, ASME, New York, 1995, pp. 99-105.

[8] Heris S. Z., Edalati Z., Noie S. H., Mahian O. Experimental investigation of $\mathrm{Al}_{2} \mathrm{O}_{3}$ /water nanofluid through equilateral triangular duct with constant wall heat flux in laminar flow, Heat Transfer Engineering, Vol. 35, No. 13, 2014, pp. 1173-1182.

[9] Heris S. Z., Esfahany M. N., Etemad S. G., Experimental investigation of convective heat transfer of $\mathrm{Al}_{2} \mathrm{O}_{3}$ /water nanofluid in circular tube, Int. J. of Heat and Fluid Flow, Vol. 28, 2007, pp. 203-210.

[10] Yul K., Park C., Kim S., Song H., Jeong H., CFD analysis of nanofluid forced convection heat transport in laminar flow through a compact pipe, IOP Conf. Series, Journal of Physics, Vol. 885, 2017, Paper No. 012021.

[11] Hwang K. S., Jang S. P., Choi S. U. S. Flow and convective heat transfer characteristics of water-based $\mathrm{Al}_{2} \mathrm{O}_{3}$ nanofluids in fully developed laminar flow regime, Int. J. of Heat and Mass Transfer, Vol. 52, No. 1-2, 2009, pp. 193-199.

[12] Wen D., Ding Y. Experimental investigation into convective heat transfer of nanofluids at the entrance region under laminar flow conditions, Int. J. Heat. Mass. Transf, Vol. 47, No. 24, 2004, pp. 5181-5188. 
[13] Pak B. C., ChoY. I. Hydrodynamic and heat transfer study of dispersed fluids with submicron metallic oxide particle, Experimental Heat Transfer, Vol. 11, No. 2, 1998, pp. $151-170$.

[14] Aakdag U., Akcay S., Demiral D. Heat transfer in a triangular wavy channel with $\mathrm{CuO} /$ water nanofluids under pulsating flow, Thermal Science, 2017, DOI: https://doi.org/10.2298/TSCI161018015A

[15] Patel H. E., Sundararajan T., Pradeep T., Dasgupta A., Dasgupta N., Das S. K. A microconvection model for thermal conductivity of nanofluids, Pramana, J. of Physics, Vol. 65, No. 5, 2005, pp. 863-869.

[16] Behroyan I., Ganesan P, H. S., Sivasankaran S. Turbulent forced convection of Cu-water nanofluid: CFD model comparison, Int. Comm. In heat and mass Transf, Vol. 67, 2015, pp. 163-172.

[17] Santra A. K., Sen S., Chakraborty N. Study of heat transfer due to laminar flow of copperwater nanofluid through two isothermally heated parallel plates, Int. J. Therm. Sci, Vol. 48, No. 2, 2009, pp. 391-400.

[18] Santra A. K., Sen S., Chakraborty N. Study of heat transfer augmentation in a differentially heated square cavity using copper-water nanofluid, Int. J. Therm. Sci, Vol. 47, No. 9, 2008, pp. 1113-1122.

[19] Velagapudi V., Konijeti R. K., Aduru C. S. K. Empirical correlations to predict thermophysical and heat transfer characteristics of nanofluids, Thermal Science, Vol. 12, No 2, 2008, pp. 27-37.

[20] Shah R. K., London A. L., Laminar flow forced convection in ducts, Advances in heat transfer, in A source book for compact heat exchanger analytical data, Ed. Irvine T., Hartnett J.P. Academic Press, New York, 1978.

[21] Ramachandran K., Hussein A. M., Kadirgama K., Ramasamy D., Azmi W. H., Tarlochan F., Kadirgama G. Thermophysical properties measurement of nano cellulose in ethylene glycol/water, Applied Thermal Engineering, Vol. 123, 2017, pp. 1158-1165. 